N., \& Nicolaides K. H. (2017). Analysis of cellfree DNA in maternal blood in screening for aneuploidies: updated meta-analysis. Ultrasound in Obstetrics and Gynecology, 50(3), 302-314. https://doi.org/10.1002/uog.17484

5. Han S. H., Kang J. S., An J. W., Lee A., Yang Y. H., Lee K. P., \& Lee K. R. (2016). Rapid prenatal diagnosis of chromosome aneuploidies in 943 uncultured amniotic fluid samples by fluorescence in situ hybridization (FISH). Journal of Genetic Medicine, 5(1), 47-54. http://www. koreamed.org/SearchBasic.php?RID $=2184447$

6. Hassold T., \& Hunt P. (2001). To err (meiotically) is human: The genesis of human aneuploidy. Nature Reviews Genetics, 2(4), 280291. https://doi.org/10.1038/35066065

7. Neagos D., Cretu R., Sfetea R. C., \& Bohiltea
L. C. (2011). The importance of screening and prenatal diagnosis in the identification of the numerical chromosomal abnormalities. Maedica, 6(3), 179-184. https:// pubmed.ncbi.nlm.nih.gov/ 22368694

8. Trân Đức Phấn, Trương Quang Đạt, Phạn Thanh Phương, Lương Thị Lan Anh, Nguyến Xuân Hùng, Hoàng Thu Lan, Nguyến Thị Lâm (2016). Tình hình dị tật bẩm sinh ở Thanh Khê Đà nănng, Phù Cát - Bình Định và Biên Hòa. Y học thực hành. 1027 (11), 154-i57.

9. Screening for Fetal Chromosomal Abnormalities: ACOG Practice Bulletin Summary, Number 226. (2020). Obstetrics \& Gynecology, 136(4). https:// journals.Iww.com/ greenjournal/Fulltext/ 2020/10000/ Screening_for_ Fetal_Chromosomal_Abnormalities_.40.aspx

\title{
ĐÁNH GIÁ KẾT QUẢ CHĂM SÓC SẢN PHỤ VÀ MộT Số YẾU Tố LIÊN QUAN TẠI BỆNH VIỆN QUÂN Y 103
}

\section{TÓM TẮT}

Mục tiêu: Đánh giá kết quả chăm sóc sản phụ trong chuyển dạ, ngay sau sinh và một số yếu tố liên quan tại Bệnh viên Quân y 103. Đối tượng, phương pháp nghiên cứu: Nghiên cứu mô tả tiến cứu, thức hiện từ tháng 11 năm 2020 đến tháng 04 năm 2021 trển 288 sản phu trong chuyển da và ngay sau sinh tai Khoa Phụ Sản - Bệnh viện Quân y 103. Dữ liệu thu thâp gôm: Kết quả hoat đông chăm sóc; Môt số yếu tố liên quan đến kết quả chăm sóc... Kết quả: Tỷ lệ chăm sóc tốt đạt $80,9 \%$. Các yếu tố liên quan: Nhóm điều kiên kinh tế ôn định kết quả chăm sóc tốt gấp 6,906 lần nhóm điêu kiện kinh tế thiếu; Có mối liên quan tới kết quả chăm sóc của: số lần đẻ và việc phá thai $(p<0,05)$; Nhóm sản phu tâm lý thoải mái kết quả chăm sóc tốt gấp 4,295 lần nhóm sản phụ tâm lý lo lắng, căng thẳng; Có mối liên quan giữa thời gian chuyến da và kết quả chăm sóc $(p<0,05)$; Nhóm sản phụ dấu hiệu sinh tồn bình thường kết quả chăm sóc tốt gấp 2,402 lần nhóm dấu hiệu sinh tồn không bình thường; Có mối liên quan giữa mức độ đau và kết quả chăm sóc sản phụ $(p<0,05)$; Nhóm sản phụ vỡ ối đúng lúc kết quả chăm sóc tốt gấp 2,57 lần nhóm võ ối non, võ̃ sớm; Có mối liên quan giữa thời gian ră̆n đẻ với kết quả chăm sóc sản phụ $(p<0,05)$; Nhóm sản phu hoc lớp tiền sản kết quả chăm sóc tốt gấp 2,287 lẩn nhóm không học. Kết luận: Tỷ lệ chăm sóc tốt $80,9 \%$. Các yếu tố liên quan kết quả chăm sóc: Điều kiện kinh tế; Số lần đẻ và phá thai; Tâm lý sản

\section{${ }^{1}$ Trường Đại họ Thăng Long}

²Bệnh viện Quân y 103

Chịu trách nhiệm chính: Trần Thị Thu Trang

Email: trangtrang 656@gmail.com

Ngày nhận bài: 7.4.2021

Ngày phản biên khoa học: 24.5.2021

Ngày duyệt bài: 8.6.2021

\section{Trần Thị Thu Trang1, Nguyễn Viết Trung ${ }^{2}$}

phụ; Tham gia học lớp tiền sản; Thời gian chuyển dạ; Dấu hiệu sinh tồn; Mức độ đau; Ối vỡ non, vỡ sớm; Thời gian ră̆n đẻ;

Tứ khóa: sản phụ, chuyển dạ, chăm sóc

\section{SUMMARY}

EVALUATION OF THE RESULTS OF

\section{MATERNAL CARE AND SOME RELATED}

\section{FACTORS AT 103 MILITARY HOSPITAL}

Objectives: To evaluate the results of maternal care in labor, right after birth and some related factors at Military Hospital 103. Subjects, research method: Prospective descriptive study conducted from November 2020 to April 2021 on 288 pregnant women during labor and immediately after birth at the Obstetrics and Gynecology Department - Military Hospital 103. Collected data includes: Results of care activities; some factors related to care outcomes. Results: Good care's percentage accounted for $80.9 \%$. Related factors: The group with good economic conditions got 6.906 times better care results than the group with poor economic conditions. There is a relationship with the outcome of care of number of births and abortions $(p<0.05)$; The group of psychologically comfortable pregnant women had 4.295 times better care results than the group of anxious and stressed maternity; There is a relationship between the time of labor and the outcome of care ( $p$ $<0.05$ ). The group of pregnant women with normal vital signs had 2.402 times bettercare results than the group with abnormal vital signs. There is a relationship between pain level and outcome of maternal care $(p<$ $0.05)$. The group of women whose membranes broke at the right time had 2.57 times better care results than that of the group with premature rupture of membranes. There is a relationship between the time of push and the outcome of maternal care $(p<0.05)$; The group of pregnant women who attended the antenatal 
class had 2.287 times better care results than the group that did not. Conclusion: The proportion of good care was $80.9 \%$. Factors related to care outcomes: economic conditions, number of births and abortions, maternal psychology, participation in antenatal classes, duration of labor, vital signs, level of pain, premature rupture of membranes, time of push to give birth.

Keywords: Maternity, labor, care.

\section{I. ĐĂT VẤN ĐỀ}

Mang thai và sinh đẻ là một quá trình sinh lý bình thường [1] nhưng lại tiềm ẩn nhiều nguy cơ đối với sức khỏe, sự sống còn của cả me và thai nhi. Trên thế giới, mỗi năm có khoảng 385.000 phụ nữ tử vong trong quá trình mang thai và sinh nở, 64 triệu phụ nữ bị biến chứng khi sinh [2].

Tại Việt Nam ngành y tế đã đạt được thành tựu đáng kể trong công tác chăm sóc sức khỏe sinh sản, tuy nhiên tỉ lệ tử vong mẹ còn cao: 69/100.000 trẻ đẻ sống [3].

Bệnh viện Quân y 103 là Bệnh viện đa khoa hang I, mỗi năm khoa Phụ Sản tiếp nhận khoảng 3000 sản phụ đến sinh. Việc chăm sóc sản phụ trước, trong và sau sinh được thực hiện theo khuyến cáo của Tổ chức $Y$ tế thế giới và Bộ $Y$ tế. Với mong muốn đánh giá kết quả và tìm hiểu các yếu tố liên quan qua đó nâng cao kết quả chăm sóc sản phụ, chúng tôi tiến hành đề tài với mục tiêu: "Đánh giá kết quả chăm sóc sản phụ trong chuyển dạ, ngay sau sinh và một số yếu tố liên quan tại Bệnh viện Quân y 103".

II. ĐỐl TƯợNG VÀ PHƯƠNG PHÁP NGHIÊN CứU

2.1. Đối tượng nghiên cứu: Các sản phụ được theo dõi chuyển dạ, sinh thường, sinh đường âm đạo tại khoa Phụ Sản - Bệnh viện Quân y 103.

2.2. Địa điểm và thời gian nghiên cứu

-Thời gian nghiên cứu: Từ tháng 11 năm 2020 đến tháng 4 năm 2021.
-Địa điểm nghiên cứu: Khoa Phụ Sản - Bệnh viện Quân y 103.

2.3. Thiết kế nghiên cứu: Nghiên cứu mô tả, tiến cứu.

2.4. Cõ̃ mẫu và chọn mẫu: Áp dụng chọn mẫu thuận tiện. Lấy toàn bộ sản phụ đáp ứng tiêu chuẩn lựa chọn trong thời gian nghiên cứu. Tổng số 288 sản phụ.

2.5. Tiêu chí đánh giá: Đánh giá kết quả chăm sóc dựa trên các tiêu chí:

- Thực hiện đầy đủ công việc chăm sóc theo quy định?

- Có suy thai, ngạt thai?

- Toàn trạng sản phụ (dấu hiệu sinh tồn)?

- Co hồi tử cung? Sản dịch?

- Tình trang tiểu tiên?

- Tình trạng vết khâu tầng sinh môn?

2.6. Xử lý số liệu. Nhập số liệu bằng phần mềm EPIDATA 3.1, phân tích số liệu bằng phần mềm STATA 13.0. Dùng các thuật toán: $\lambda$ test, $t$ test so sánh các giá trị và các tỷ lệ...

2.7. Đạo đức nghiên cứu. Đối tượng nghiên cứu được giải thích về mục đích nghiên cứu. Mọi thông tin được bảo mật và chỉ phục vụ cho nghiên cứu. Đề cương nghiên cứu được Hội đồng Đạo đức trường Đại học Thăng Long và Bệnh viện Quân y 103 thông qua.

\section{KẾT QUẢ NGHIÊN CỨU}

\subsection{Kết quả chăm sóc sản phụ}

Bảng 3.1. Đánh giá kết quả chăm sóc sản phu

\begin{tabular}{|c|c|c|}
\hline Kết quả chăm sóc sản phụ & $\mathbf{n}$ & $\mathbf{\%}$ \\
\hline Tốt & 233 & 80,9 \\
\hline Không tốt & 55 & 19,1 \\
\hline Tống & $\mathbf{2 8 8}$ & $\mathbf{1 0 0}$ \\
\hline
\end{tabular}

Nhận xét: $80,9 \%$ sản phụ được chăm sóc tốt trong và sau sinh.

\subsection{Một số yếu tố liên quan đến kết quả chăm sóc sản phụ}

Bảng 3.2. Mối liên quan giứa đặc điểm chung với kêt quả chăm sóc sản phụ

\begin{tabular}{|c|c|c|c|c|c|c|}
\hline \multirow{3}{*}{ Điêuu kiện kinh tế } & \multicolumn{4}{|c|}{ Kết quả chăm sóc } & \multirow{3}{*}{$\begin{array}{c}\text { OR } \\
\text { (CI 95\%) }\end{array}$} & \multirow{3}{*}{$\mathbf{p}$} \\
\hline & \multicolumn{2}{|c|}{ Không tốt } & \multicolumn{2}{|c|}{ Tốt } & & \\
\hline & $\mathbf{n}$ & $\%$ & $\mathbf{n}$ & $\%$ & & \\
\hline Thiếu & 15 & 55,56 & 12 & 44,44 & 6,906 & 0,000 \\
\hline Đủ & 40 & 15,33 & 221 & 84,67 & $3,010-15,845$ & \\
\hline
\end{tabular}

Nhận xét: Nhóm điều kiện kinh tế ôn định kết quả chăm sóc sản phụ tốt gấp 6,906 lần nhóm điều kiện kinh tế thiếu $(\mathrm{OR}=6,906 ; 95 \% \mathrm{CI}: 3,010-15,845 ; \mathrm{p}<0,05)$.

Bảng 3.3. Mối liên quan giữa tiền sử sản khoa với kêt quả chăm sóc sản phỵ

\begin{tabular}{|c|c|c|c|c|c|c|}
\hline \multirow{3}{*}{ Tiên sử sản khoa } & \multicolumn{4}{|c|}{ Kết quả chăm sóc } & \multirow{3}{*}{$\begin{array}{c}\text { OR } \\
\text { (CI 95\%) }\end{array}$} & \multirow{3}{*}{$\mathbf{p}$} \\
\hline & \multirow{2}{*}{\multicolumn{2}{|c|}{ Không tốt }} & \multicolumn{2}{|c|}{ Tốt } & & \\
\hline & & & $\mathbf{n}$ & $\%$ & & \\
\hline \multicolumn{7}{|c|}{ Đẻ thường, đẻ đường âm đạo } \\
\hline Chưa đẻ & 19 & 27,94 & 49 & 72,06 & 1 & \\
\hline 1 lần & 18 & 12,77 & 123 & 87,23 & $2,649(1,264-5,550)$ & 0,007 \\
\hline
\end{tabular}




\begin{tabular}{|c|c|c|c|c|c|c|}
\hline \multicolumn{7}{|c|}{ Phá thai } \\
\hline Có & 15 & 37,5 & 25 & 62,5 & \multirow{2}{*}{$3,12(1,512-6,435)$} & $\mathbf{0 , 0 0 2}$ \\
\hline Không & 40 & 16,13 & 208 & 83,87 & 30 \\
\hline
\end{tabular}

Nhận xét: Có mối liên quan giữa số lần đẻ thường, đẻ đường âm đạo $(\mathrm{OR}=2,649 ; 95 \% \mathrm{CI}$ : $1,264-5,550 ; \mathrm{p}<0,05)$ và việc phá thai $(\mathrm{OR}=3,12 ; 95 \% \mathrm{CI}: 1,512-6,435 ; \mathrm{p}<0,05)$ với kết quả chăm sóc sản phụ.

Bảng 3.4. Mối liên quan giữa đặc điểm tâm lý với kết quả chăm sóc sản phụ

\begin{tabular}{|c|c|c|c|c|c|c|}
\hline \multirow{3}{*}{ Tâm lý sản phụ } & \multicolumn{4}{|c|}{ Kết quả chắm sóc } & \multirow{3}{*}{$\begin{array}{c}\text { OR } \\
\text { (CI 95\%) }\end{array}$} & \multirow{3}{*}{$\mathbf{p}$} \\
\hline & \multicolumn{2}{|c|}{ Không tốt } & \multicolumn{2}{|c|}{ Tốt } & & \\
\hline & $\mathbf{n}$ & $\%$ & $\mathbf{n}$ & $\%$ & & \\
\hline Lo lắng, căng thắng & 32 & 35,96 & 57 & 64,04 & & 0.001 \\
\hline Thoải mái & 23 & 11,56 & 176 & 88,44 & $2,326-7,933$ & \\
\hline
\end{tabular}

Nhân xét: Nhóm sản phụ tâm lý thoải mái kết quả chăm sóc tốt gấp 4,295 lần nhóm tâm lý lo lắng, cằng thẳng ( $\mathrm{OR}=4,295 ; 95 \% \mathrm{CI}: 2,326-7,933 ; \mathrm{p}<0,05)$.

Bảng 3.5. Mối liên quan giữa đặc điểm chuyển dạ với kêt quả chăm sóc

\begin{tabular}{|c|c|c|c|c|c|c|}
\hline \multirow{3}{*}{$\begin{array}{l}\text { Đặc điểm } \\
\text { chuyển dạ }\end{array}$} & \multicolumn{4}{|c|}{ Kết quả chăm sóc } & \multirow{3}{*}{$\begin{array}{c}\text { OR } \\
\text { (CI 95\%) }\end{array}$} & \multirow{3}{*}{$\mathbf{p}$} \\
\hline & \multicolumn{2}{|c|}{ Không tốt } & \multicolumn{2}{|c|}{ Tốt } & & \\
\hline & $\mathbf{n}$ & $\%$ & $\mathbf{n}$ & $\%$ & & \\
\hline \multicolumn{7}{|c|}{ Thời gian chuyến dạ } \\
\hline Kéo dài & 10 & 40,0 & 15 & 60,0 & 1 & \\
\hline Ngắn & 11 & 11,0 & 89 & 89,0 & $5,39(1,844-15,776)$ & 0,04 \\
\hline Bình thường & 34 & 20,86 & 129 & 79,14 & $2,52(1,03-6,208)$ & 0,035 \\
\hline \multicolumn{7}{|c|}{ Dấu hiệu sinh tôn trong chuyến dạ } \\
\hline Không bình thường & 14 & 32,56 & 29 & 67,44 & $2402(1168-4938)$ & 0,017 \\
\hline Bình thường & 41 & 16,73 & 204 & 83,27 & & \\
\hline \multicolumn{7}{|c|}{ Mức độ đau trong chuyến dạ } \\
\hline Đau nhiều & 14 & 58,33 & 10 & 41,67 & 1 & \\
\hline Đau vừa & 32 & 20,25 & 126 & 79,75 & $5,51(2,143-14,174)$ & 0,0001 \\
\hline Đau ít, không đau & 9 & 8,49 & 97 & 91,51 & $15,09(4,388-51,885)$ & 0,0001 \\
\hline
\end{tabular}

Nhận xét: - Có mối liên quan có ý nghĩa thống kê giữa thời gian chuyến dạ với kết quả chăm sóc sản phụ $(\mathrm{p}<0,05)$.

-Nhóm sản phụ dấu hiệu sinh tồn bình thường kết quả chăm sóc tốt gấp 2,402 lần nhóm dấu hiệu sinh tồn không bình thường (95\%CI: 1,168-4,938; $\mathrm{p}<0,05)$.

-Có mối liên quan giữa mức độ đau trong chuyển dạ và kết quả chăm sóc sản phụ $(p<0,05)$.

Bảng 3.6. Môi liên quan giữa đặc điểm trong sinh với kêt quả chăm sóc

\begin{tabular}{|c|c|c|c|c|c|c|}
\hline \multirow{3}{*}{$\begin{array}{l}\text { Đặc điểm trong } \\
\text { sinh }\end{array}$} & \multicolumn{4}{|c|}{ Kết quả chăm sóc } & \multirow{3}{*}{$\begin{array}{c}\text { OR } \\
\text { (CI 95\%) }\end{array}$} & \multirow{3}{*}{$\mathbf{p}$} \\
\hline & \multicolumn{2}{|c|}{ Không tốt } & \multicolumn{2}{|c|}{ Tốt } & & \\
\hline & $\mathbf{n}$ & $\%$ & $\mathbf{n}$ & $\%$ & & \\
\hline \multicolumn{7}{|c|}{ Thời gian rặn đẻ } \\
\hline Kéo dài & 19 & 51,35 & 18 & 48,65 & 1 & \\
\hline Ngắn & 8 & 9,64 & 75 & 90,36 & $9,89(3,289-29,77)$ & 0,0001 \\
\hline Bình thường & 28 & 16,67 & 140 & 83,33 & $5,278(2,359-11,807)$ & 0,0001 \\
\hline \multicolumn{7}{|c|}{ Tình trạng ối } \\
\hline Võ ối non, sớm & 18 & 32,73 & 37 & 67,27 & $2,57(1,326-5,005)$ & 0,005 \\
\hline 8 & 37 & 1 & 196 & 12 & $2,5 /(1,3<0-5,005)$ & 0,005 \\
\hline
\end{tabular}

Nhận xét: - Nhóm sản phụ vỡ ối đúng lúc kết quả chăm sóc tốt cao gấp 2,57 lần nhóm võ ối non, vỡ sớm (95\%CI: 1,326-5,005; p < 0,05).

- Tìm được mối liên quan có ý nghĩa thống kê giữa thời gian rặn đẻ với kết quả chăm sóc sản phụ $(p<0,05)$.

Bảng 3.7. Môii liên quan giữa việc học lớp tiền sản với kêt quả chăm sóc

\begin{tabular}{|c|c|c|c|c|c|c|}
\hline \multirow{3}{*}{ Tham gia lớp tiên sản } & \multicolumn{4}{|c|}{ Kết quả chăm sóc } & \multirow{3}{*}{$\begin{array}{c}\text { OR } \\
\text { (CI 95\%) }\end{array}$} & \multirow{3}{*}{ p } \\
\hline & \multicolumn{2}{|c|}{ Không tốt } & \multicolumn{2}{|c|}{ Tốt } & & \\
\hline & $\mathbf{n}$ & $\%$ & $\mathbf{n}$ & $\%$ & & \\
\hline Không tham gia lớp học & 35 & 25,74 & 101 & 74,26 & 2,2 & ng \\
\hline Có tham gia lớp học & 20 & 13,18 & 132 & 86,82 & $1,245-4,198$ & 0,008 \\
\hline
\end{tabular}


Nhận xét: Nhóm sản phụ tham gia lớp hoc tiền sản có kết quả chăm sóc tốt cao gấp 2,287 lần nhóm sản phụ không tham gia $(95 \% \mathrm{CI}$ : 1,245-4,198; $p<0,05)$.

\section{BÀN LUÂ̂N}

4.1. Đánh giá kết quả chăm sóc sản phụ. 80,9\% sản phụ được chăm sóc tốt (bảng 3.1). Điều này cho thấy công tác chăm sóc sản phụ được đánh giá qua 6 tiêu chí tại Khoa Phụ SảnBệnh viện Quân y 103 là khá tốt. $100 \%$ sản phụ trong nghiên cứu được tư vấn, hướng dẫn giáo dục sức khỏe, chăm sóc về tinh thần, vệ sinh cá nhân, chăm sóc về dinh dưỡng, thực hiện các kĩ thuật điều dưỡng, theo dõi đánh giá người bệnh theo Thông tư 07 của Bộ Y tế [4]. Kết quả này tương đương kết quả chăm sóc trong nghiên cứu của Lê Thu Đào [5]...

\subsection{Một số yếu tố liên quan đến kết quả chăm sóc đối tượng nghiên cứu}

4.2.1. Mối liên quan giữa điều kiện kinh tế với kết quả chăm sóc. Nhóm sản phụ có thu nhập và điều kiện kinh tế ổn định có kết quả chăm sóc tốt gấp 6,906 lần nhóm có điều kiện kinh tế thiếu (OR=6,906; 95\%CI: 3,010 15,$845 ; p<0,05-$ bảng 3.2.). Kết quả này cho thấy sản phụ điều kiện kinh tế ổn định, có thu nhập tốt, tâm lý thoải mái, sẽ không lo lắng về chi phí lúc nhập viện, chỉ tập chung vào cuộc đẻ với mục tiêu có được sơ sinh khỏe mạnh nên dễ dàng hợp tác với nhân viên y tế nhờ vậy kết quả chăm sóc sẽ tốt. Nếu sản phụ điều kiện kinh tế khó khăn, lo lắng về vấn đề chi phí khi nằm viên, tâm lý sẽ không thoải mái, sự hợp tác với nhân viên y tế hạn chế làm ảnh hưởng đến kết quả chăm sóc.

4.2.2. Mối liên quan giữa tiền sử sản khoa với kết quả chăm sóc. Có mối liên quan giữa số lần đẻ thường, đẻ đường âm đạo với kết quả chăm sóc sản phụ $(\mathrm{OR}=2,649 ; 95 \% \mathrm{CI}$ : 1,264 - 5,550; $p<0,05$ - bảng 3.3). Nhóm sản phụ đã đẻ 1 lần có kết quả chăm sóc tốt cao gấp 2,649 lân những sản phụ chưa đẻ lần nào. Nhóm sản phụ chưa sinh lần nào chưa từng trải qua đau đớn của cuộc đẻ, chưa có kinh nghiêm vượt can, tâm lý lo lắng, căng thẳng... nên việc hợp tác với nhân viên y tế không tốt bằng những sản phụ đã qua sinh nở vì vậy kết quả chăm sóc kém hơn.

Nghiên cứu cũng tìm được mối liên quan giữa phá thai với kết quả chăm sóc $(\mathrm{OR}=3,12$; 95\%CI: $1,512-6,435 ; p<0,05)$. Những sản phụ không có tiền sử phá thai có kết quả chăm sóc tốt gấp 3,12 lần so với sản phụ đã từng phá thai. Ngoài những sang trấn tâm lý do lần phá thai trước, những ảnh hưởng của phá thai có thể tác động đến sự làm tổ của phôi, vị trí bám của bánh rau... khi chuyển dạ có thể ảnh hưởng đến cơn co tử cung, bình chỉnh ngôi... cần nhiều sự can thiệp nhiều vào cuộc đẻ do đó dễ làm kết quả chăm sóc bị ảnh hưởng.

4.2.3. Mối liên quan giữa đặc điểm tâm lý với kết quả chăm sóc sản phụ. Nhóm sản phụ tâm lý thoải mái có kết quả chăm sóc tốt gấp 4,295 lần nhóm sản phụ tâm lý căng thẳng $(\mathrm{OR}=4,295 ; 95 \% \mathrm{CI}: 2,326-7,933 ; \mathrm{p}<0,05-$ bảng 3.4).

Khoảng $10 \%$ sản phụ sau sinh bị ức chế tâm lý, có thể sẽ gặp nhiều rối loạn: khó tiểu, bí tiểu, đau do co bóp tử cung, đau do vết khâu tầng sinh môn, mệt mỏi do vừa trải qua cuộc đẻ, ám ảnh về khả năng chăm sóc con, khó tập trung, rối loạn giấc ngủ... ảnh hưởng đến kết quả chăm sóc [6].

4.2.4. Mối liên quan giữa đặc điểm chuyển dạ và kết quả chăm sóc. Có mối liên quan giữa thời gian chuyển dạ với kết quả chăm sóc $(p<0,05)$. Sản phụ có thời gian chuyển da ngắn và bình thường kết quả chăm sóc tốt gấp 5,39 lần và 2,52 lần sản phụ có thời gian chuyển dạ kéo dài (bảng 3.5). Chuyển dạ kéo dài làm cho sản phụ mệt mỏi, lo lắng, đau lâu, tử cung căng giãn trong nhiêu giờ, yếu tố tâm lý... sau sinh dể ảnh hưởng đến co hồi tử cung, sản dịch, khó tiểu hay bí tiểu...[7].

Kết quả nghiên cứu cũng thấy mối liên quan giữa nhóm sản phụ dấu hiệu sinh tồn trong chuyển dạ bình thường kết quả chăm sóc tốt cao gấp 2,402 lần nhóm dấu hiệu sinh tồn không bình thường (95\%CI: 1,168 - 4,938, p < 0,05 - bảng 3.5). Các thông số sống nếu ổn định rõ ràng là minh chứng cho hiệu quả của quá trình chăm sóc và cũng là yếu tố thuận lợi cho công tác theo dõi, chăm sóc sản phụ ở giai đoạn kế tiếp.

Kết quả bảng 3.5 cũng cho thấy có mối liên quan giữa mức độ đau trong chuyển dạ với kết quả chăm sóc sản phụ $(p<0,05)$. Nhóm sản phụ có mức độ đau vừa có kết quả chăm sóc tốt cao gấp 5,51 lần nhóm sản phụ đau nhiều. Nhóm sản phụ đau ít, không đau có kết quả chăm sóc tốt cao gấp 15,09 lần so với nhóm sản phụ đau nhiều. Tình trạng nhóm sản phụ đau ít, khổng đau có kết quả chăm sóc tốt cao gấp nhiều lần so sới nhóm sản phụ đau nhiều khẳng định đau ảnh hưởng rất lớn đến quá trình chăm sóc. Khi sản phụ đau nhiều, tâm lý sẽ mất kiểm soát, sự hợp tác với nhân viên y tế ở mức giới hạn nên không thực hiện tốt các hướng dẫn của nhân viên y tế. 
4.2.5. Mối liên quan giữa đăc điểm trong sinh với kết quả chăm sóc. Kểt quả bảng 3.6 cho thấy nhóm sản phụ võ̃ ối đúng lúc có kết quả chăm sóc tốt cao gấp 2,57 lần nhóm vỡ ối non, võ sớm (95\%CI: 1,326 - 5,005; $p<0,05$ ). Như vậy nghiên cứu tìm được mối liên quan giữa tình trạng vỡ ối với kết quả chăm sóc.

Cùng với đặc điểm ối vỡ, nghiên cứu cũng tìm được mối liên quan có ý nghĩa thống kê giữa thời gian rặn đẻ với kết quả chăm sóc sản phụ ( $p$ $<0,05)$. Nhóm sản phụ có thời gian rặn đẻ ngắn và bình thường có kết quả chăm sóc tốt cao gấp nhiêu lần nhóm sản phụ có thời gian rặn đẻ kéo dài $(\mathrm{OR}=9,89 ; 95 \% \mathrm{CI}: 3,289-29,77 ; \mathrm{p}<0,001)$ và $(O R=5,278 ; 95 \% C I: 2,359-11,807 ; p<0,001)$. Sản phụ có thời gian rặn đẻ lâu, kéo dài sẽ mệt, mất sức và đau nhiều, sự hợp tác với nhân viên y tế thường không tốt nên kết quả chăm sóc kém hơn các sản phụ có thời gian rặn đẻ ngắn và bình thường.

4.2.6. Mối liên quan giữa học lớp tiền sản và kết quả chăm sóc sản phụ. Tìm hiểu mối liên quan giữa học lớp tiền sản với kết quả chăm sóc, kết quả nghiên cứu cho thấy nhóm sản phụ/chồng/cả hai vợ chồng tham gia lớp học tiên sản có kết quả chăm sóc tốt cao gấp 2,287 lần nhóm cả hai vợ chồng không tham gia học $(\mathrm{OR}=2,287 ; 95 \% \mathrm{CI}: 1,245-4,198 ; \mathrm{p}<0,05-$ bảng 3.7).

Những sản phụ đã tham gia học lớp tiền sản, quá trình tư vấn, hướng dẫn các sản phụ của nhân viên y tế rất thuận lợi, sản phụ và người nhà hợp tác khá tốt. Sản phu thường hiểu rõ diễn biến cuộc chuyển dạ, có sự sẵn sàng về tâm lý, biết được những thay đổi của cơ thể qua mỗi giai đoạn, chuẩn bị kĩ về thể chất và tinh thần để chào đón em bé. Sản phụ có thể vượt can dễ dàng vì đã hợp tác toàn diện với nhẩn viên y tế nên biết thực hành đúng cách thở, cách rặn đẻ, cách giảm đau, cách chăm sóc sơ sinh....

\section{KẾT LUẬN}

Kết quả nghiên cứu cho thấy số sản phụ được chăm sóc tốt chiếm tỉ lệ cao $80,9 \%$.

Nghiên cứu đã xác định được một số yếu tố: Điều kiện kinh tế, số lần đẻ, tình trạng phá thai, tâm lý sản phụ, tham gia học lớp tiền sản, thời gian chuyển dạ, dấu hiệu sinh tồn, mức độ đau, ối võ̃ non-võ sớm, thời gian rặn đẻ có mối liên quan có ý nghĩa thống kê với kết quả chăm sóc sản phụ của nhân viên y tế.

\section{TÀI LIẸU THAM KHẢO}

1. Bộ môn Phụ Sản, Học viện Quân y (2019), Băi giảng sản phụ khoà, Nhà xuất bản Quân đội nhân dân, Hà Nôi.

2. UNICEF (2009), Sức khỏe bà me và trẻ sơ sinh

3. Bộ Y tế (2018), Báo cáo hộ sinh Việt nam lần thứ nhất.

4. Bô Y tế (2011), Thông tư số 07 , Hướng dẫn công tác điểu dưỡng chăm sóc người bênh trong bệnh viện.

5. Lê Thu Đào (2012), Nghiền cứu tình hình chăm sóc bà me và trẻ sơ sinh sau mổ lấy thai tại Bênh viện đa khoa Trung ương Cần Thơ, Trường đại học Y Dước Cần Thơ.

6. Trân Thị Thu Hà (2014), Chăm sóc me và bé sơ sinh, Sổ tay 2 , Trung tâm nghiên cứu, đào tạo và phát triển công đồng.

7. Đào Nguyển Hùng (2017), Nghiên cứu vai trò người trơ sinh trong chuyến da và sau sinh tai Bệnh viện Quân y 103, Đê tài khoa học cấp Học viện Quấn y.

\section{KẾT QUẢ ỨNG DỤNG NEURONAVIGATION PHẪU THUẬT U BÁN CẦU ĐẠI NÃO}

TÓM TẮT

Mục tiêu: Nhận xét kết quả ứng dụng hệ thống Neuronavigation phẫu thuật u bán cầu đại não. Phương pháp: Mô tả cắt ngang, kết quả phẫu thuật 72 bệnh nhân u bán câu đại não có sử dụng hệ thống

\footnotetext{
*Trường Đại học Y Dược Thái Bình

**Bênh viện Việt Đức

Chiu trách nhiệm chính: Vũ Minh Hải

Email: vuminhhai777@gmail.com

Ngày nhận bài: 5.4.2021

Ngày phản biện khoa học: 24.5.2021

Ngày duyệt bài: 4.6.2021
}

\section{Dương Như Năm*, Vũ Minh Hải*, Đồng Văn Hệ***}

Neuronavigation trong phẫu thuật tại bệnh viện Việt Đức từ 10/2015 đến tháng 3/2016. Kết quả: 72 bẹnh nhân u bán cầu đại não gồm 27 nam (37,5\%), 45 nữ $(62,5 \%)$; Tuổi trung bình là $48,6 \pm 13,4$. Giải phẫu bệnh: 38 u màng não; 28 u thần kinh đệm; 5 u di cắn; Mức đô cắt bỏ u: $76,4 \%$ lấy toàn bô u, 18,1\% lấy u gần toàn bộ bảo vệ các cấu trúc quan trọng; Thời gian phẫu thuâte trung bình là $163,47 \pm 84,64$ phút; Thời gian điêu trị sau mổ trung bình là 7,06 $\pm 2,19$ ngày; 93\% bệnh nhân không phải truyền máu; 12,5\% biến chứng sau mổ; Kết quả sau mổ 3 tháng: Tốt $(55,6 \%)$, di chứng nhẹ $(31,9 \%)$ và $87,5 \%$ bệnh nhân có cải thiện chất lượng cuộc sống sau mổ (Karnofsky nhóm I, II). Kết luận: Ứng dụng Neuronavigation trong phẫu thuật u não bán cầu đại não giúp phẫu 